\title{
EDitorial
}

\section{A construção do médico contemporâneo}

Desde o início da graduação, todo aluno de medicina tem o objetivo de tornar-se um indivíduo de excelência no meio acadêmico e profissional. Somos impelidos a buscar uma formação sólida e de referência, que possibilite a criação do alicerce imprescindível para compor o médico diferenciado.

Com esse propósito, a reclusão do aluno no ensino tradicional é cada vez mais insuficiente, pois não estimula o indivíduo a deixar sua zona de conforto e a buscar a integralidade fundamental ao bom profissional da atualidade. Nessa perspectiva, os congressos médicos acadêmicos têm se difundido gradativamente, e se fazem indispensáveis à medida que estimulam experiências sociais e científicas e permitem o intercâmbio de vivências de seus participantes.

O Brazilian International Congress of Medical Students (BRAINCOMS) é uma inciativa dos alunos da Escola Paulista de Medicina, com a finalidade de promover o primeiro congresso brasileiro internacional do meio acadêmico, de modo a proporcionar uma experiência ímpar na formação de seus organizadores e congressistas. Inspirado no International Student Congress of (bio)Medical Sciences (ISCOMS), incentivamos a produção científica, a sensibilização e a socialização dos alunos de mais de 23 países, e contamos com a presença de professores de instituições renomadas do Brasil e do exterior.

A nossa parceria com a Revista de Medicina da FMUSP tem papel indispensável no incentivo à submissão de pesquisas pelos congressistas, dada a possibilidade de publicação dos melhores trabalhos e ao prestígio do periódico. Dessa forma, temos então mais um fator de encorajamento dos alunos a aspirarem a um desempenho além dos moldes arcaicos do ensino clássico de medicina.

Juntos, BRAINCOMS e Revista de Medicina, estamos impulsionando a formação integrada do médico excepcional.

Michelle Gioia Coiado Majewski

Coordenadora do Comitê Científico BRAINCOMS 2017

$4^{\circ}$ ano Escola Paulista de Medicina, turma 82

Universidade Federal de São Paulo

Email: michelle.coiado@gmail.com 